\title{
Technology Roadmap Applied in R\&D Projects
}

\author{
Carlos Ariel BAEZ ${ }^{\mathrm{a}, 1}$, Rodrigo Bueno OTTO ${ }^{\mathrm{b}}$, Felipe Pinheiro da SILVA ${ }^{\mathrm{b}}$ and \\ Eduardo Cesar DECHECHI ${ }^{\mathrm{c}}$ \\ anstituto de Tecnologia Aplicada e Inovação - ITAI, Brazil \\ ${ }^{\mathrm{b}}$ Fundação Parque Tecnológico Itaipu - Brasil, Brazil \\ ${ }^{\mathrm{c}}$ Universidade Estadual do Oeste do Paraná - UNIOESTE, Brazil
}

\begin{abstract}
An increasing number of studies have highlighted the importance of using Technology Roadmapping as a tool to support Strategic Management and Innovation. There is a direct relationship between the Strategic Management of Innovation in organizations, with the use of tools and methods to support decision making, communication, and technological actions. In this context, we aim at exploring the environment of the Laboratory of Automation and Simulation of Electrical Systems (LASSE) of the Itaipu Technology Park Foundation (FPTI) Brazil, mentioning its importance, analogy, and adherence to the modernization plan of the ITAIPU Hydroelectric Power Plant. In a qualitative way, the main perspectives for LASSE were drawn. The alternative proposed by this work is to define a Technology Roadmap (TRM) architecture to LASSE / FPTI, to align different levels and visions. A functional perspective, specific to its needs, that help the manager to plan solutions and identify the best path for technological development.
\end{abstract}

Keywords. Technology Roadmapping, Research and Development, Portfolio, Strategy

\section{Introduction}

Companies seek to develop competitive factors by aligning strategies with the market. The competitiveness of the company tends to be guided by the capacity to innovate, in response to the needs of the market and the growing of competition [1]. For a vital issue, organizations draw up plans that integrate market, business, product, technology, and resource perspectives. An effort that requires the collection of information with different stakeholders of an organization, aiming at the definition of working methods, tools of measurement and structuring of their processes, even quality, so that there is a common understanding about the implementation of their strategy [1].

According to [2], the strategy used is the formal planning techniques, known as strategic planning, and it is the ideal method to discipline managers to look ahead and to express goals in resource allocation, encouraging the achievement of long-term objectives and the evolution of short-term plans. In addition, [3] summarizes the theme in one sentence, "planning does not concern future decisions but the future implications of present decisions" it is important to reflect how this concept should be considered in

\footnotetext{
${ }^{1}$ Corresponding Author, Email: carlosariel.bz@gmail.com.
} 
third sector organizations, research and development environments, laboratories, institutes and universities in search of innovative results for technological development, without the competitive market factor in its strategy. [2, 3]

Porter [4] sees innovation as a competitive advantage for organizations that explore the theme in the broadest sense, embracing new technologies and new ways of doing things. Complementing formal and innovative planning, authors who explore "learning organizations" suggest sharing visually the strategy with the team. [5] says that organizations that stimulate shared visions, generate commitment and concern in a broad way, presenting answers and solutions close to the best hypothesis, demonstrating the flexibility to solve problems, developed jointly among the stakeholders. [4, 5]

In the context of innovation management, organizations have sought to use tools and methodologies that assist in scenario analysis, competitive intelligence and technology prospecting, the roadmap has been supporting the development of this concept. According to [6] the roadmap is a tool of business structure that allows to visualize the evolution of a certain subject to be explored, giving support to the innovation of strategic character. One of the differentials of the tool is its ability to allow an integrated view of the market, the products and the technology of a certain subject. The roadmap was disseminated by [7] at Motorola.

The purpose of the development of this work, it is opportune to apply a systematic planning tool to support technological development in an R \& D laboratory of FPTI Brazil, LASSE - Laboratory of Automation and Simulation of Electrical Systems. This study will become adherent to the strategy, by making explicit the LASSE as an action of the FPTI and executing solution of technological applications in the ITAIPU Hydroelectric Power Plant, in the automation and simulation subject and monitoring systems with support to the technological modernization of the power plant as quoted in its strategic objective 8 (Foster research and innovation for energy and technology development, with emphasis on sustainability).

The development of the work will have actions of information gathering and interpretation of strategic information (data collection, feedback and analysis) followed by intervention actions in the research environment, action plan, implementation [8].

The main objective of this work is the conceptual, preliminary and prospective evaluation of a TRM architecture model applied to the strategic management of the Laboratory of Automation and Simulation of Electrical Systems.

For the development of this study will be treated after the introduction in the topics the following topics: 2.0 Conceptual description; 2.1 Strategic Management of Innovation; 2.2 Technological Roadmapping; 2.3 Roadmap structure; 3.0 Description and characterization of the Laboratory of Automation and Simulation of Electrical Systems.

\section{Conceptual Description}

This article presents the strategic management of innovation, its importance for decisionmaking and mechanisms for the development of the technological strategy, unfolding the definition of the Technological Roadmapping and the various ways of structuring its architecture. The bibliographic research was used as a basis to present the concepts described in this detail. 


\subsection{Strategic Management of Innovation}

Tidd et al. [9] define innovation as the ability to establish relationships, detect opportunities and take advantage of them, and can be classified in the "4 Ps" of innovation: product innovation; process innovation; positioning innovation; paradigm innovation.

According to [10], innovation encourages the emergence of new products and services that together with technological change create the conditions for new markets. Still, according to the author, the basis of innovation is the entrepreneur, who sees change as the norm and as being sound.

For Tidd et al [9], innovation is a necessary process for all companies (goods and services). The authors suggest a simplified model of the innovation process that can be used by all companies, whose model is composed of three steps: (i) demand: it is up to the company to look for signs of change in the market that may interest you. They can be threats or opportunities (new technological opportunities, political pressures, competitors, etc.); (ii) selection: choosing between threats and opportunities prioritizing those that most converge with firm strategies; (iii) implementation: where the idea will be effectively transformed into product, service, new method or change in the business model. According to the authors, the company seeks in the competitive environment in which is inserted information for its knowledge, technology, and creativity that can develop new values and solutions in order to maintain or expand its position in the market profitably.

According to [11], to innovate the company needs to have ideas and in addition, it is necessary to select them, considering the existing competencies that will guarantee its development, the competitiveness of the organization, market perspectives, and integration to the business strategy. To innovate, it is important that the ideas selected are adherent to the organization's strategy and what the market is craving (market pull). Tidd; Bessant [12] argues that organizations need to structure innovation management processes to enable the creation of new products and processes more assertively. In this sense, the organization needs to align its innovative efforts with the company's strategies and ensure that the results expected and defined in the initial planning are fulfilled at the end of the process $[11,12,13]$.

Corroborating, [14] describes that management of innovation is complex and there are no universal solutions, and it is a challenge for managers to adopt best practices to the context of each organization. It is important for the coordinators to have a broad vision when the subject is strategic management of innovation, the perception of several levels makes planning assertive, the means to structure visually the best way for decision making is to use visual tools such as Roadmap.

\subsection{Technology Roadmapping}

The process of development of technological maps (roadmapping) is the practice of roadmap elaboration, it is based on a map with a broad look to the future on a defined theme, being realized with the help of specialists of specific themes. In addition, the roadmap communicates visions and features that will be needed for the business. According to Phaal et al. [15], the roadmap is a business structure tool that allows visualizing the evolution of a particular subject to be explored and mapped, being a powerful and flexible tool that supports innovation and strategy. Walsh [16] defines the roadmap as the process that represents the strategic and technological vision, being the 
first managerial tool that unifies the visions of product, technology, and strategy $[15,6$, $16]$.

According to [17] Technology Roadmapping (TRM) is a needs-driven technology planning process that helps identify, select and develop technological alternatives to meet the developmental needs of a product. It brings together a team of experts who develop a framework for organizing and delivering critical information and technology needed for decision-making regarding technology investments and how to leverage those investments. Complementing, [18] describes the technology roadmap as a roadmap format with more industry-oriented applications, allowing an evolutionary understanding of the market, the products, and technologies involved, along with the links and discontinuities between different perspectives.

The Technology Roadmapping approach is very flexible, and the terms 'product' or 'business' can be used and integrated with a variety of ways. The analysis by [18] compared a set of approximately 40 roadmaps and revealed a number of different applications, grouped into eight general areas: Product planning; Service planning; Strategic planning; Long-term planning; Knowledge management planning; Program planning; Process planning; Integration planning.

The approach of technology roadmapping has undergone significant evolutions since its initial development in Motorola in the '70s. In this sense, much of this evolution is due to the experiences of large corporations from different sectors such as the internet, automotive, energy, software, among others. However, these evolutions are based on a better understanding of the process of elaboration and customization of roadmapping $[19,18]$.

Based on this evolution, the technological roadmap is also widely used as a market- oriented research and development (R\&D) planning process, with a focus on the identification, selection, and structuring of technological alternatives that satisfy a set of needs of the product. Identifying emerging technologies and setting development goals in specific areas of technology requires more sophisticated tools such as benchmarking, gap analysis, portfolio analysis, bibliometrics, patent data mining, Delphi and expert decisions [20].

By the variety of applications, structures and forms of Roadmap used by the organizations, the following item describe the hybrid composition used by the main authors of the theme in order to model the proposal applied to the R\&D Laboratory being studied.

\subsection{Roadmaps Structures}

The architecture for building a Roadmap is broad and flexible, the definition of this structure depends basically on the need, goal, and context that one wishes. The graphics formats, generally used for Roadmap communication, are basically developed by eight types of structures, as described by [18]: a. Multiple layers; b. Structure in Bars; c. Tables; d. Graphic; and. Figurative models; f. Flowcharts; g. Single layer; H. Texts [19].

Based on the mentioned models the multilayer structure will be described for better understanding, being of common use and have greater adherence to the objective of this article:

a. Multiple layers: The common form of roadmap used as shown in Figure 1 is composed of a series defined by layers, such as technology, product, and market. This Rodmapping model allows integration between each layer to occur, exploring interlayer 
dependencies, facilitating the connection between technology, products, services, and business needs.

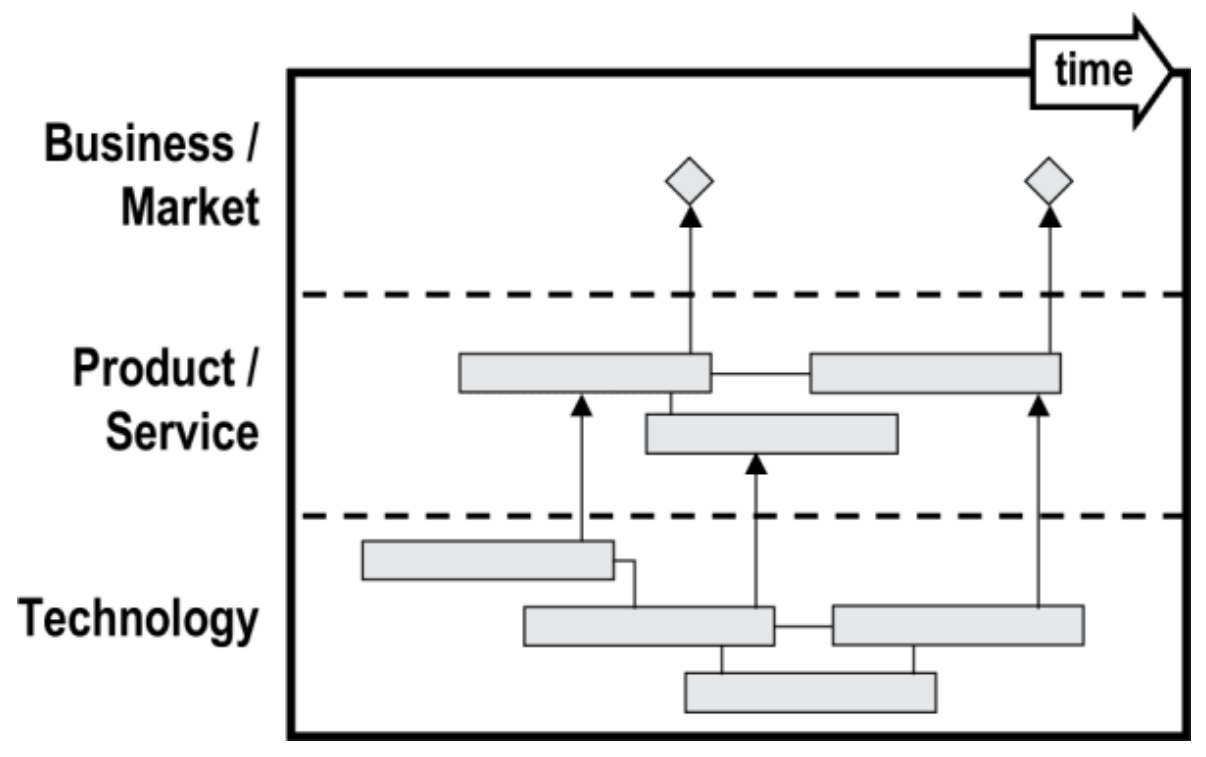

Figure 1. Roadmap structure of "Multiple layers".

The most common approach to defining a Roadmap is the structure in generic form, as described in "Multiple layers." The generic model is a time-based chart that comprises several layers that usually include commercial and technological perspectives. The roadmap allows the evolutionary description of the markets, products, and technologies to be explored that need to be interconnected. This structure reflects the vision of the future designed by the company, of easy understanding and communication for the whole organization [21].

It is important to emphasize that technological roadmaps aim at expressing and communicating effectively the predictions about technological and strategic plans. Their use is a powerful practice of decision support, as they reflect the challenges established by strategic technological planning.

It can be used even as a means of communication and mobilization of teams for operational actions in an integrative process, allows the organization to be aware of the problems and the provisions about the technological planning of form (key departments like marketing, production, $R \& D$, clear. In addition, the described models present a fraction of the elements that make up the multilayer structure integrally, being possible the architecture customization based on the context of the application.

\section{Characterization of the Laboratory of Automation and Simulation of Power Systems}

The Laboratory of Automation and Simulation of Electrical Systems - LASSE composes the structure of Research and Development in Innovation belonging to the Itaipu Technological Park Foundation (FPTI - Brazil). This laboratory was created to 
meet the demands in the area of energy, testing, simulation of electrical systems and digital automation, mainly to support actions of the Technological Update Plan of the ITAIPU Hydroelectric Power Plant and provide technical services of the electric sector in general, specifically Brazil and Paraguay.

The laboratory does not have its own legal personality, and it is being operated and maintained by FPTI - Brazil, in which it has other centers, laboratories and research environments on its management. The PTI Foundation has as its characteristic the structure of the "matrix" organization or a hybrid organization chart, constituted with common operational areas as accounting; financial; purchasing; human resources among other areas. They support research projects and environments such as LASSE.

Reaching the goal of implementation, with enough structure and technology to perform R\&D in automation and real-time simulations, there is also the expansion of the technical team in the current agreement for twenty-one employees of the FPTI working in LASSE. The expansion of customer service is natural, currently, agreements have been reached with energy distributor ANEEL2 and cooperation agreements with research institutes and universities that have related themes, helping to develop new lines of research and consolidating existing competencies.

Based on these characteristics, the consolidation of LASSE as an entity of Technology and Innovation Center - C, T \& I (meeting the demands of the Brazilian Electricity Sector) is demonstrated. The following topic proposes the layered architecture of the Roadmap that best fits the LASSE.

\section{Proposed Roadmap Structure}

According to the characteristics of the Laboratory of Automation and Simulation of Electrical Systems - LASSE, its purpose is evident, as well as the evolution of its competencies and consolidation of the technological structure for FPTI mainly for ITAIPU. Despite the brief description presented, it is understood that LASSE is a mean for achieving the strategies, belonging to a complex environment, where its actions and results are shared between ITAIPU / FPTI and other indirect customers interested in the R\&D deliverables of this laboratory. The structure of the Roadmap of this scenario should consider this context, following it will be detailed the layers of the architecture proposed by this work, highlighting the functional perspectives to compose a model.

\subsection{Strategic and commercial perspective}

The top layer corresponds to the commercial strategic perspective, which the main purpose is to gather related information from the Market (external environment) and the Business (internal environment). In general, LASSE acts directly to meet the internal needs of two organizations: the first is PTI Foundation and the second ITAIPU, by the characteristics of the agreements signed between both institutions.

As for market information, the Laboratory has been providing Simulation services to companies in the Electrical sector, as well as Research \& Development projects among them in ANEEL's own R\&D.

According to the characteristics presented, the first layer that corresponds to the justification and motivation of the development of new products, the "why?", Explains the PTI Foundation in order to highlight the strategic actions that the LASSE contributes through the development of its activities. Soon after, it performs the same for ITAIPU, 
focusing on the applications and contributions of its development to the UHI technological update plan. Finally, the architecture presents the "Electric Sector", to map the market contributions that LASSE can integrate, be it with services, partnerships, and research.

In this sense, the survey for detailing the structure may present needs for new research, and expansion of the competence and technologies existing in the LASSE, for this reason, the importance of the continuity of the exploration in this layer.

\subsection{Portfolio perspective}

This layer is the intermediary, it has the total correlation with the upper and lower layer because it comprises the characteristics of the products, services or applications developed by the laboratory. It basically refers to the portfolio of existing and planned projects in LASSE, wherein this architecture has highlighted the lines of research developed which are as follows:

- Electrical Engineering:

- Power Systems Simulations - PSS;

- Distributed Generation - DG;

- Digital Automation:

○ Instrumentation;

- Monitoring Systems;

- Automation and Control Protection Systems - ACP;

- Phasor measurement.

Both lines have Research and Development projects, which consider the technological and research perspectives to compose the portfolio that corresponds to the "what will be done" by LASSE. In this sense, the following sub-item will deal with the technologies Competencies and Knowledge belonging to the Laboratory.

\subsection{Perspective of Competence and Technology}

For the survey of this layer, we opted for an exploratory study developed with the technical team, operational of the scientific and technological activities of LASSE.

The approach used in the explanation of the team, as well as the resources available in the laboratory, was applied to present a realistic view of the people effectively linked to the actions of the Laboratory. As the LASSE competence base is already consolidated, this result leads to a reliable reading of the real situation and expectation. Although there are technicians and specialists with little time to perform in the "LASSE" others with little time of experience, the results can be considered faithful to the real situation.

The study was performed as follows:

a. A pre-structured spreadsheet with two "flaps" was prepared. One for each theme, the first one for the survey of existing technologies in the laboratory and the other for the survey of skills. Each of the themes had a rating to encourage the team to define as many keywords as possible. The application was initially made with the awareness of the whole team about the importance of gathering information. The spreadsheet was then shared via the Web to all employees, who later edited it. 
b. After the information collection period, the data collected were validated. For this stage were elected leaders of the teams of Automation Technology; Engineering circuit development; Electrical Power System; PSS Systems Engineering and an engineer responsible for basic research projects.

c. After the compilation of the obtained material, it was observed the indication of the LASSE:

- 53 technologies that make up the structure raised as essential, market differential, use in business and constant updating.

- 40 different competencies (notice that it was not the objective of this action to qualify the topic, being a potential study object).

d. All items were classified by team leaders, in large groups, of themes in common:

- $\quad$ Testing of electrical sector equipment (Control and Monitoring Protection);

- Industrial Automation (monitoring);

- Electronics (signal conditioning and shipping);

- Software development;

- $\quad$ Electrical studies.

In addition to defining the means of how to develop products and services through technology and skills resources, a sub-layer was created to explain the partnerships and collaborations between universities that conduct joint research; the research institutes that work directly connected in the development of the projects; evidencing the partner companies, which are composed of exclusive suppliers or developers participating in projects or interested in replication of the developed products (spin-offs).

In addition, there was a prominence for third parties, which corresponds to the technical development that is required to hire other companies for a specific accomplishment. Finally, business areas for sale and marketing of services provided by LASSE.

\section{Final Considerations, Limitations, and Recommendations}

The present work had the objective to develop a proposal of the structure of Technological Roadmap to the Laboratory of Automation and Simulation of Electrical Systems. For that, the perspectives of the resources were analyzed, specifically the structure and competence, the perspectives of the projects with the portfolio of products and services, and finally, the strategic perspective on the vision and institutional adherence.

In general, with the data collection, it was possible to identify, classify and group the existing resources in the laboratory. With the application of the control levers of Simons (1995), it was possible to identify the adherence of laboratory collaborators with the formal institutional purpose. The survey of the portfolio explained the formal projects in the laboratory and its commitment to the maintainer having the impact of its projects linked to the dual strategy highlighted in the work by the Itaipu Technological Park Foundation and ITAIPU Binacional [22]. 
The conclusion reached with the findings of this research reveals a set of high- level structural resources, with applied development projects of great relevance to ITAIPU Binacional and other partners, in which the laboratory needs a strategic non- market theme driver the lack of formal data. From a practical point of view, the results can bring to managers, project team and key stakeholders an integrative view on the various perspectives around the laboratory, being possible to replicate them, as well as to use it as a visual and strategic communication tool. among teams, managers and partners in the development of integrated projects.

Finally, the limitations and recommendations of the study are listed. As the objective of the research was to present a Roadmap model to LASSE through a qualitative methodology, new research could be carried out using complementary tools, such as prospective, patient-based research, obtaining a future vision for updating existing scenarios and using projects and products already applied and developed.

\section{References}

[1] E. Vasconcellos, Gerenciamento da Tecnologia: Um instrumento para a competitividade empresarial. Blucher, São Paulo, 1999.

[2] H. Mintzberg, A estruturação das organizações. In: H. Mintzberg, J.B. Quinn, O Processo Da Estratégia. 3. ed., Bookman, Porto Alegre, 2001.

[3] D. de Pinho Rebouças Oliveira, Planejamento estratégico: conceitos, metodologia e Práticas. Atlas, São Paulo, 2007.

[4] M.E. Porter, Competição: estratégias competitivas essenciais. Campus, Rio de Janeiro, 1999.

[5] P.M. Senge, A Quinta Disciplina: arte e prática da organização que aprende. 23 ed. BestSeller, Rio de Janeiro, 2008.

[6] R. Phaal, C. Farrukh, D.R. Probert, Roadmapping for strategy and innovation. Aligning technology and markets in a dynamic world. University of Cambridge, 2010.

[7] C.H. Willyard and C.W. McClees, Motorola's Technology Roadmap Process. Research Management, 1987, Vol. 30, pp. 13-19.

[8] S.M.A. Roesch, Projetos de estágio e de pesquisa em administração: guia para estágios,trabalhos de conclusão, dissertações e estudos de caso. Atlas, São Paulo, 2009.

[9] J. Tidd, J. Bessant and K. Pavitt, Gestão da Inovação. 3 ed. Bookman, Porto Alegre, 2008.

[10] P.F. Drucker, Inovação e espírito empreendedor: práticas e princípios. De Cultura, São Paulo, 1998.

[11] P.L. de Andrade Coutinho, T. Longanezi, J.V. Bomtempo and F.M.A. Pereira, Construindo um Sistema de Gestão da Inovação Tecnológica: Atividades, Estrutura e Métricas. Revista ADM.MADE, ano 8, 12 (3), p.19-49, 2008. http://www.anpad.org.br/admin/pdf/FGI499.pdf.

[12] N. Wognum, C. Bil, F. Elgh, M. Peruzzini, J. Stjepandić and W.J.C Verhagen, Transdisciplinary systems engineering: implications, challenges and research agenda, International Journal of Agile Systems and Management, Vol. 12, 2019, No. 1, pp. 58-89.

[13] V. Theis, D. Schreiber, A inovação e as alternativas de realizar as atividades em p\&d: estudo de caso da braskem. Gestão Contemporânea, nº 2,2015.

[14] K. Goffin and R. Mitchell, Innovation management strategy and implementation using the pentathlon framework. Palgrave Macmillan, New York, 2010.

[15] R.N. Kostoff and R.R. Schaller, Science and technology roadmaps. IEEE Transactions on Engineering Management, 2001, Vol. 48, No. 2, p. 132-143.

[16] S.T. Walsh, Portfolio Management for the Commercialization of Advanced Technologies. Engineering Management Journal, 2001, Vol. 13, No. 1, pp. 33-37.

[17] O.H. Bray and M.L. Garcia, Technology roadmapping: the integration of strategic planning for competitiveness. PICNET - Portland International Conference on Management and Technology, 1997.

[18] R. Phaal, C. Farrukh, D.R. Probert, Technology roadmapping - A planning framework for evolution and revolution. Technological Forecasting and Social Change, Vol. 71, pp. 5-26, 2004.

[19] R. Phaal, C. Farrukh, D.R. Probert, Technology Roadmapping: linking technology resources to business objectives. Centre for Technology Management, University of Cambridge, 2001.

[20] Y. Cho, S.P. Yoon and K.S. Kim, An industrial technology roadmap for supporting public R\&D planning. Technological Forecasting and Social Change, Vol. 107, 2016, pp. 1-12. 
[21] M. Luggen, Technology and Innovation Management in New Technology-Based Firms: Introducing the PockeTM Concept, PhD thesis, ETH Zürich, 2004.

[22] E. Damke Jr., E.D. da Silva and S.A. Walter, Sistemas de controle e alinhamento estratégico: proposição de indicadores. Revista Eletrônica de Estratégia \& Negócios, 2011, Vol. 4, No.1, pp. 65-87. 